Retraction

\title{
Retracted: Coronary Angiography Safety between Transradial and Transfemoral Access
}

\author{
Cardiology Research and Practice
}

Received 25 June 2018; Accepted 25 June 2018; Published 19 July 2018

Copyright (C) 2018 Cardiology Research and Practice. This is an open access article distributed under the Creative Commons Attribution License, which permits unrestricted use, distribution, and reproduction in any medium, provided the original work is properly cited.

Cardiology Research and Practice has retracted the article titled "Coronary Angiography Safety between Transradial and Transfemoral Access" [1]. The article was found to contain a substantial amount of material from the following published articles:

C. M. S. Kabir, M. M. Haq, S. R. Khan, M. Z. Chowdhury, M. L. Ali, and M. R. Karim, "Safety of radial vs. femoral artery access in coronary angiography," Bangladesh Heart Journal, vol. 30, no. 2, pp. 68-73, 2016, doi: 10.3329/bhj.v30i2.28814 (not cited).

M. Brueck, D. Bandorski, W. Kramer, M. Wieczorek, R. Höltgen, and H. Tillmanns, "A randomized comparison of transradial versus transfemoral approach for coronary angiography and angioplasty," JACC: Cardiovascular Interventions, vol. 2, no. 11, pp. 1047-1054, 2009, doi: 10.1016/j.jcin.2009.07.016 (not cited).

There are also concerns with the reporting of the study design. The methods state "It was prospective, randomized, single-centre study conducted in the Department of Cardiology, LPS Institute of Cardiology, GSVM Medical College, Kanpur, U.P, India, where all cases of diagnostic coronary angiography (CAG) of 1997 consecutive patients for various reasons over a 12-month period (from January 2015 till the end of December 2015) were reviewed for this analysis," but then that "The choice between transfemoral or transradial artery access was operator's discretion with right radial approach being the default strategy." These are mutually exclusive approaches to treatment allocation, that is, randomization versus surgeon discretion. Additionally, a trial registration number is not included.

We were unable to contact the authors.

\section{References}

[1] S. K. Sinha, V. Mishra, N. Afdaali et al., "Coronary angiography safety between transradial and transfemoral access," Cardiology Research and Practice, vol. 2016, Article ID 4013843, 7 pages, 2016. 


\title{
Coronary Angiography Safety between Transradial and Transfemoral Access
}

\author{
Santosh Kumar Sinha, Vikas Mishra, Nasar Afdaali, Mukesh Jitendra Jha, Ashutosh \\ Kumar, Mohammad Asif, Ramesh Thakur, and Chandra Mohan Varma
}

Department of Cardiology, LPS Institute of Cardiology, G.S.V.M. Medical College, Kanpur, Uttar Pradesh 208002, India

Correspondence should be addressed to Santosh Kumar Sinha; fionasan@rediffmail.com

Received 31 July 2016; Accepted 18 September 2016

Academic Editor: Robert Chen

Copyright (C) 2016 Santosh Kumar Sinha et al. This is an open access article distributed under the Creative Commons Attribution License, which permits unrestricted use, distribution, and reproduction in any medium, provided the original work is properly cited.

Background and Aim. The aim of study was to evaluate safety, feasibility, and procedural variables of transradial approach compared with transfemoral approach in a standard population of patients undergoing coronary catheterization as one of the major criticisms of the transradial approach is that it takes longer overall procedure and fluoroscopy time, thereby causing more radiation exposure. Method. Between January 2015 and December 2015, a total of 1,997 patients in LPS Institute of Cardiology, GSVM Medical College, Kanpur, UP, India, undergoing coronary catheterization were randomly assigned to the transradial or transfemoral approach. Result. Successful catheterization was achieved in 1045 of 1076 patients (97.1\%) in the transradial group and in 918 of 921 patients (99.7\%) in the transfemoral group $(p=0.001)$. Comparing the transradial and transfemoral approaches, fluoroscopy time $(2.46 \pm 1.22$ versus $2.83 \pm 1.31 \mathrm{~min} ; p=0.32)$, procedure time $(8.89 \pm 2.72$ versus $9.33 \pm 2.82 \mathrm{~min} ; p=0.56)$, contrast volume $(67.52 \pm 22.54$ versus $71.63 \pm 25.41 \mathrm{~mL} ; p=0.32)$, radiation dose as dose area product $\left(24.2 \pm 4.21\right.$ versus $\left.22.3 \pm 3.46 \mathrm{Gycm}^{2} ; p=0.43\right)$, and postprocedural rise of serum creatinine $(6 \pm 4.5 \%$ versus $8 \pm 2.6 \% ; p=0.41)$ were not significantly different while vascular access site complications were significantly lower in transradial group than transfemoral group (3.9\% versus $7.6 \% ; p=0.04)$. Conclusion. The present study shows that transradial access for coronary angiography is safe among patients compared to transfemoral access with lower rate of local vascular complications.

\section{Introduction}

Following the first report of radial coronary angiography by Campeau in 1989 and radial percutaneous coronary intervention (PCI) by Kiemeneij et al. in 1992, there is an increase in use of transradial access (TRA) because of lower access site bleeding, patient preference and satisfaction, early ambulation, reduced morbidity, and lower procedural cost over transfemoral approach around the world [1-3]. Lower mortality as shown in RIVAL trial with transradial coronary angioplasty (TRA) in acute coronary syndrome patients gives additional boost to it [4]. Most of the studies of the transradial approach have been performed through right radial route because of familiarity in performing the study from the patient's right side as commonly used in femoral approach though it can be done from left radial route as well. But it is not totally immune from criticism and complications. One of major criticisms of transradial approach is that it takes longer overall procedure and fluoroscopy time, which means more radiation exposure to cath lab personnel as they will also stand close to patient where rates of radiation scattered will be higher [5] So, the aim of this study was to evaluate the safety of transradial approach versus transfemoral approach in routine coronary angiography practice in terms of crossover rate from one to the other, contrast amount, overall procedure time, fluoroscopy time, and complications.

\section{Material and Method}

2.1. Design. It was prospective, randomized, single-centre study conducted in the Department of Cardiology, LPS Institute of Cardiology, GSVM Medical College, Kanpur, U.P, India where all cases of diagnostic coronary angiography (CAG) of 1997 consecutive patients for various reasons over a 12 month period (from January 2015 till the end of December 2015) were reviewed for this analysis. The study protocol 


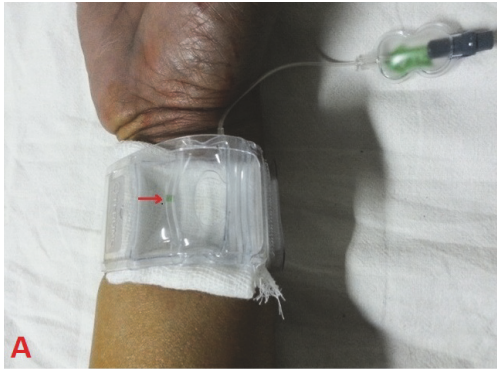

(a)

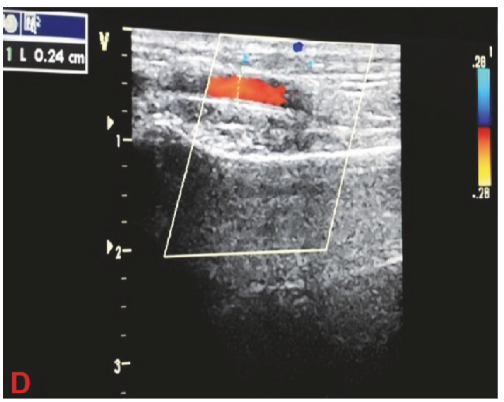

(d)

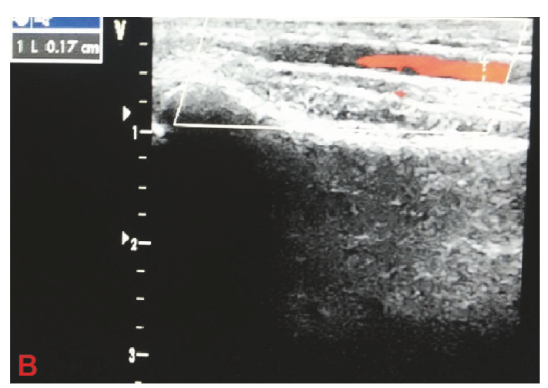

(b)

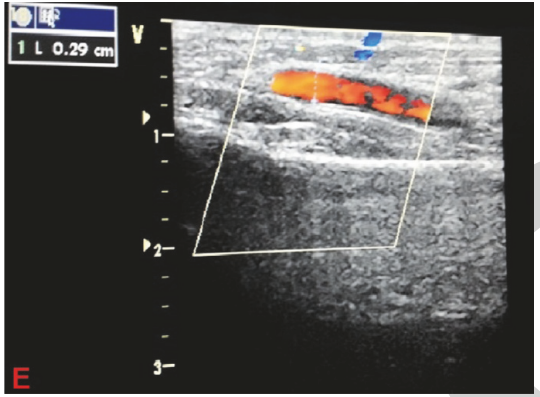

(e)

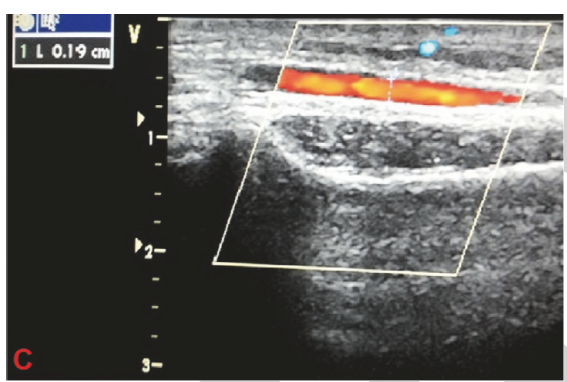

(c)

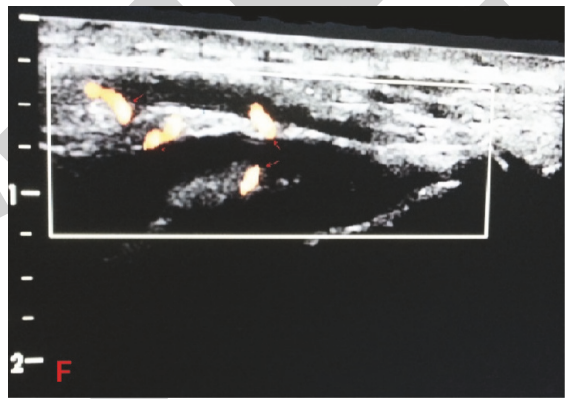

(f)

FIGURE 1: (a) TR band; various internal diameters of radial artery (b, c, d, and e); RAO with collaterals (f).

was approved by the local ethics committee and followed the Declaration of Helsinki after obtaining informed consent from each patient.

2.2. Procedure. Enrolled patients underwent comprehensive cardiac evaluation including CAG as a part of their diagnostic procedure and those who underwent subsequent PCI among ad hoc group were excluded. The choice between transfemoral or transradial artery access was operator's discretion with right radial approach being the default strategy. Transfemoral approach was favoured for patients with abnormal Allen test and with coronary artery bypass grafts (CABG).

Radial artery was punctured by $21 \mathrm{G}$ needle and $0.021^{\prime \prime}$ guide wires (Cordis, USA) were inserted. 5-F sheath and 6-F sheath were used for diagnostic purpose and ad hoc intervention depending on need. After sheath replacement, cocktail containing $200 \mu \mathrm{g}$ nitroglycerin, $2.5 \mathrm{mg}$ diltiazem, and $2500 \mathrm{IU}$ unfractionated heparin was injected. Angiogram was performed by 5-F TIG catheter (Terumo, Japan). For those having abnormal take-off where cannulation was not possible with TIG catheter, Judkin's left or right (JL/JR) catheter was used. Radial sheath was removed just after procedure and compression was performed for $2 \mathrm{~h}$ with radial compression device (TR band; Terumo) using the "patent haemostasis" protocol proximal to puncture site (Figure 1) [4]. TR band was inflated with $15-19 \mathrm{~mL}$ of air. The patency of radial artery was checked at least once every 20 minutes by palpation and colour of palm and was removed after 2 hours of sheath removal. Light pressure bandage was applied which was removed next day.

Transfemoral procedures were performed by $5 \mathrm{Fr}$ diagnostic catheters (JL/JR). At the end of the procedure, sheath was removed and manual compression was performed until satisfactory haemostasis had been achieved followed by placement of compressive bandage with dynaplast for $6 \mathrm{~h}$. Patients were stratified into two groups, transradial and transfemoral, according to arterial access used to perform procedure. Crossover to transradial access was defined as failed access, extreme tortuosity and peripheral arterial disease (Figure 2).

Crossover to transfemoral access was defined as failure to cannulate through radial route and classified into the following three groups: puncture failure (lack of radial cannulation), radial and brachial failure (severe spasm, tortuosity, loops, remnant, or other anomalies), and epiaortic failure (severe subclavian or aortic tortuosity) (Figure 3) [6].

Procedure duration was defined as time between first needle skin contact to removal of last catheter. Total fluoroscopy time was recorded, as it is correlated to catheter manipulation. Angiographic and procedural details including severity of coronary artery disease and complexity of lesions were noted.

2.3. Statistical Evaluation. Statistical analyses were performed using the SPSS 17.0 (SPSS Inc., Chicago, Illinois). Continuous variables were analyzed using Student's $t$-test and presented as mean $\pm \mathrm{SD}$ whereas categorical variables were given as numbers (percentages). The comparison between groups was done by Mann-Whitney $U$ test for continuous variables and by Chi-square or Fisher's exact test for categorical variables. $p<0.05$ was considered statistically significant.

\section{Result}

A total of 1997 consecutive patients were enrolled where transradial approach was used in 1076 patients (53.88\%) and transfemoral approach in 921 patients (46.12\%). Baseline 


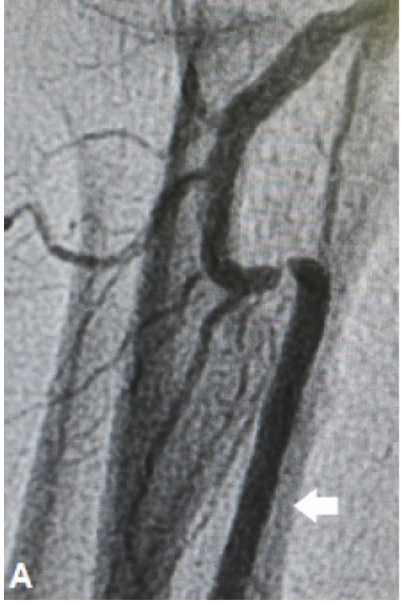

(a)

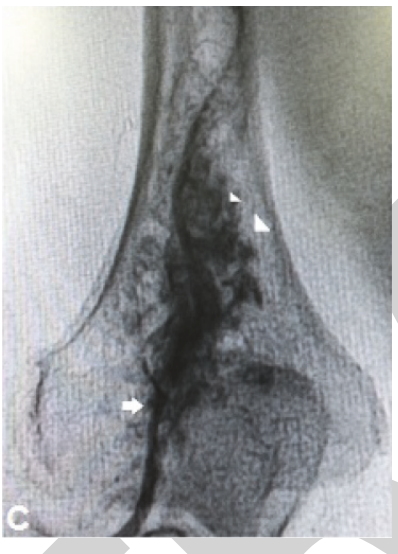

(c)

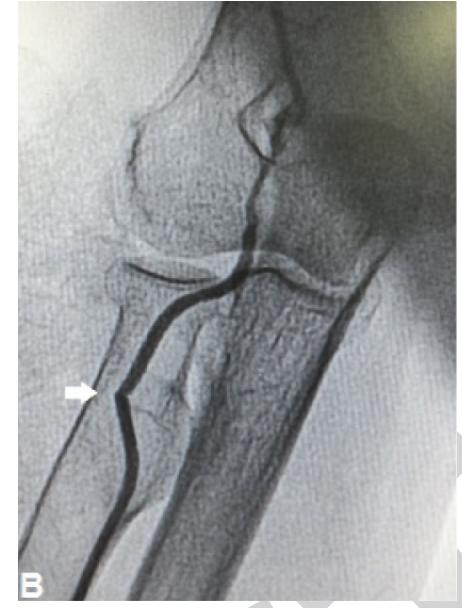

(b)

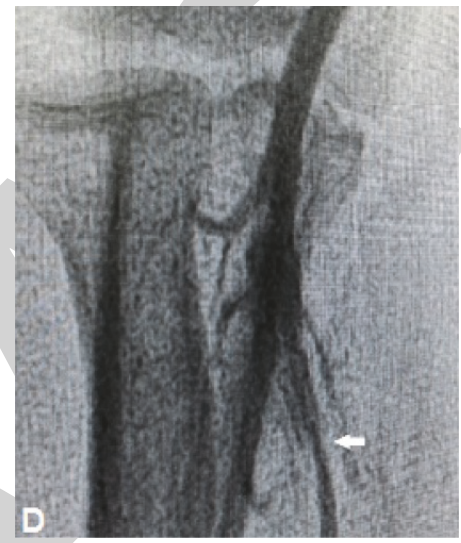

(d)

FIGURE 2: Few of the complications of transradial catheterization: vasospasm, focal (a); vasospasm, diffuse (b); perforation (c); dissection (d).

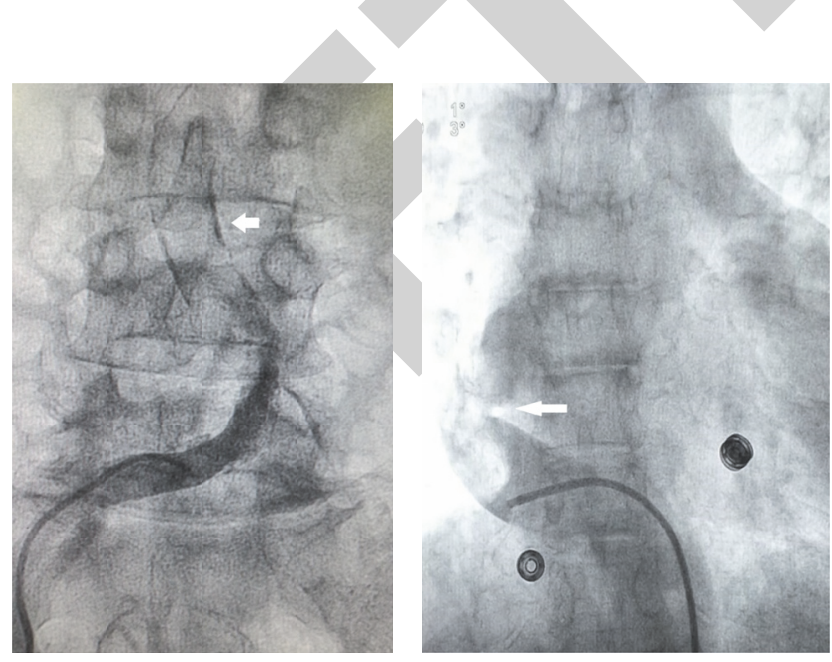

FIGURE 3: Reasons of radial crossover from transfemoral route: tortuous and calcified aorta.

characteristics of patients are summarized in Table 1, which were similar in both groups except for cardiomyopathy $(n=$ $7 ; 0.6 \%$ versus $n=38 ; 4.1 \%: p=0.05)$, post-CABG $(n=$ $7 ; 0.6 \%$ versus $n=31 ; 3.3 \%: p=0.04)$, and valvular heart disease awaiting replacement $(n=4 ; 0.3 \%$ versus $n=23 ; 2.4 \%: p=0.02$ ) which were significantly higher in transfemoral than transradial group. All transradial access in post-CABG group were done by left radial approach.

Crossover from right radial artery access to femoral approach occurred in 31 cases (2.8\%) because of puncture failure in 15 patients $(1.4 \%)$, hairpin loop in 3 patients $(0.27 \%)$, vasospasm $(0.65 \%)$ in 7 patients, and epiaortic failure in 6 patients $(0.6 \%)$ while there were $3(0.3 \%)$ crossovers in the femoral group $(p=0.001$ ) (Figure 2). Comparing the transradial and transfemoral approaches, fluoroscopy time $(2.46 \pm 1.22$ versus $2.83 \pm 1.31 \mathrm{~min}, p=0.32)$, procedure duration $(8.89 \pm 2.72$ versus $9.33 \pm 2.82 \mathrm{~min}, p=0.56)$, radiation dose $\left(24.2 \pm 4.21\right.$ versus $\left.22.3 \pm 3.46 \mathrm{Gycm}^{2}, p=0.43\right)$, contrast volume $(67.52 \pm 22.54$ versus $71.63 \pm 25.41 \mathrm{~mL}, p=$ $0.32)$, and postprocedural serum creatinine $(1.3 \pm 0.2$ versus $1.4 \pm 0.15 \mathrm{mg} / \mathrm{dL}, p=0.41$ ) were not significantly different between both transradial and transfemoral groups (Table 2).

28 patients (2.6\%) developed vasospasm who responded to additional doses of nitroglycerin and diltiazem except in 7 patients who did not respond and went crossover to transfemoral route. Radial artery occlusion (RAO) was observed in 56 patients (5.2\%) in whom pulse was palpable 
TABLE 1: Baseline characteristics of patients $(n=1997)$.

\begin{tabular}{|c|c|c|c|}
\hline Characteristic & Transradial CAG $(n=1076 ; \%)$ & Transfemoral CAG $(n=921 ; \%)$ & $p$ value \\
\hline Age (years) & $51 \pm 16.4$ & $49 \pm 14.9$ & 0.16 \\
\hline Male & $856(79.6 \%)$ & $700(71.7)$ & 0.2 \\
\hline Female & $220(20.4 \%)$ & $221(28.3)$ & 0.23 \\
\hline Height $(\mathrm{cm})$ & $166.5 \pm 10.8$ & $154 \pm 8.4$ & 0.4 \\
\hline Weight $(\mathrm{kg})$ & $63.6 \pm 11.2$ & $59.2 \pm 9.6$ & 0.18 \\
\hline $\operatorname{BMI}\left(\mathrm{kg} / \mathrm{m}^{2}\right)$ & $24.9 \pm 2.8$ & $23.8 \pm 3.6$ & 0.4 \\
\hline $\operatorname{BSA}\left(\mathrm{m}^{2}\right)$ & $1.66 \pm 0.22$ & $1.62 \pm 0.19$ & 0.24 \\
\hline Serum creatinine (mg/dL) & $1.2 \pm 0.3$ & $1.3 \pm 0.4$ & 0.4 \\
\hline \multicolumn{4}{|l|}{$C A D$ risk factors } \\
\hline Hypertension & $421(39.1)$ & $313(34)$ & 0.32 \\
\hline Diabetes mellitus & $358(33.2)$ & $268(29)$ & 0.29 \\
\hline Smokers & $323(30)$ & $323(35)$ & 0.31 \\
\hline Family history of CAD & $76(7.1)$ & $37(4)$ & 0.43 \\
\hline Dyslipidemia & $441(41)$ & $335(36.4)$ & 0.22 \\
\hline \multicolumn{4}{|l|}{ Clinical diagnosis } \\
\hline Acute coronary syndrome & $676(62.8)$ & $543(58.9)$ & 0.12 \\
\hline Chronic stable angina & $355(33)$ & $240(26.1)$ & 0.32 \\
\hline Cardiomyopathy & $07(0.6)$ & $38(4.1)$ & 0.05 \\
\hline Chest pain for evaluation & $27(2.5)$ & $46(4.9)$ & 0.53 \\
\hline Previous CABG & $07(0.6)$ & $31(3.3)$ & 0.04 \\
\hline Valvular heart disease & $4(0.3)$ & $23(2.4)$ & 0.02 \\
\hline \multicolumn{4}{|l|}{ LVEF (\%) } \\
\hline (a) $>45 \%$ & $818(76)$ & $646(70.2)$ & 0.32 \\
\hline (b) $35-45 \%$ & $120(11.2)$ & $154(16.7)$ & 0.21 \\
\hline (c) $<35 \%$ & $138(12.8)$ & $120(13.1)$ & 0.4 \\
\hline \multicolumn{4}{|l|}{ Medications } \\
\hline Aspirin & $1002(93.2)$ & $708(76.9)$ & 0.5 \\
\hline Clopidogrel & $55(50.6)$ & $636(69.1)$ & 0.3 \\
\hline Prasugrel & $132(12.3)$ & $169(18.4)$ & 0.11 \\
\hline Ticagrelor & $58(5.8)$ & $29(3.2)$ & 0.33 \\
\hline Statin & $981(91.2)$ & $722(78.4)$ & 0.7 \\
\hline Beta-blocker & $785(72.9)$ & $620(67.4)$ & 0.53 \\
\hline ACEI/ARB & $974(90.5)$ & $754(81.9)$ & 0.19 \\
\hline ССВ & $230(21.4)$ & $268(29.2)$ & 0.5 \\
\hline Aldosterone antagonist & $132(12.3)$ & $84(9.2)$ & 0.31 \\
\hline Angiographic severity of CAD (obstructive) & $743(69.1)$ & $723(78.6)$ & 0.42 \\
\hline (a) SVD & $350(47.2)$ & $420(58.2)$ & 0.18 \\
\hline (b) DVD & $212(28.6)$ & $161(22.2)$ & 0.56 \\
\hline (c) TVD & $181(20.4)$ & $104(14.3)$ & 0.67 \\
\hline (d) Left main (isolated \pm other vessel) & $41(3.8)$ & $38(5.3)$ & 0.3 \\
\hline CAD (intermediate $50-70 \%$ ) & $177(16.4)$ & $103(11.2)$ & 0.29 \\
\hline Non-obs. CAD (recanalised) & $97(8.9)$ & $38(4.2)$ & 0.44 \\
\hline Normal coronaries & $59(5.4)$ & $55(6)$ & 0.31 \\
\hline
\end{tabular}

Data presented as mean \pm standard deviation or number (percentage). $\mathrm{BMI}=$ body mass index; $\mathrm{BSA}=$ body surface area; $\mathrm{CAD}=$ coronary artery disease; $\mathrm{DM}$ = diabetes mellitus; $\mathrm{LVEF}=$ left ventricular ejection fraction; $\mathrm{ACEI}=$ angiotensin-converting enzyme inhibitor; $\mathrm{ARB}=$ angiotensin-receptor blocker; $\mathrm{CCB}=$ calcium-channel blocker; SVD = single-vessel disease; DVD = double-vessel disease; TVD = triple-vessel; CABG = coronary artery bypass graft. 
TABLE 2: Procedural and postprocedural outcome of patients $(n=1,997)$.

\begin{tabular}{|c|c|c|c|}
\hline Variables & Transradial CAG $(n=1076 ; \%)$ & Transfemoral CAG $(n=921 ; \%)$ & $p$ value \\
\hline \multicolumn{4}{|l|}{ Catheters used } \\
\hline (a) Single catheter & $1034(96.1)$ & $10(1.1)$ & 0.24 \\
\hline (b) Catheter exchanged ${ }^{*}(\mathrm{AL} / \mathrm{AR} / \mathrm{JR} / \mathrm{JL})$ & 42 (4.9.) & $911(98.9)$ & \\
\hline \multicolumn{4}{|l|}{ Crossover rate } \\
\hline (a) Radial to femoral & $31(2.9)$ & - & 0.001 \\
\hline (b) Femoral to radial & - & $3(0.3)$ & \\
\hline Duration of radial artery compression (Hr.) & $2.1 \pm 0.2$ & & 0.12 \\
\hline Fluoroscopy time (min) & $2.46 \pm 1.22$ & $2.83 \pm 1.3$ & 0.32 \\
\hline Radiation dose $\left(\mathrm{Gy} \times \mathrm{cm}^{2}\right)$ & $24.2 \pm 4.21$ & $22.3 \pm 3.46$ & 0.43 \\
\hline Procedure duration & $8.89 \pm 2.72$ & $9.33 \pm 2.82$ & 0.56 \\
\hline Contrast volume (mL) & $67.52 \pm 22.54$ & $71.63 \pm 25.41$ & 0.32 \\
\hline Local site pain & $21(1.9)$ & $38(4.1)$ & 0.04 \\
\hline Haematoma & $9(0.83)$ & $13(1.4)$ & 0.001 \\
\hline Local site paraesthesia & $13(1.2)$ & $19(2.1)$ & 0.03 \\
\hline
\end{tabular}

* Including one for crossover; UFH: unfractionated heparin; CAG: Coronary Arteriography; RAO: radial artery occlusion.

in 29 patients $(51 \%)$ on next day. Local site pain $(n=21 ; 1.9 \%$ versus $n=38 ; 4.1 \% ; p=0.04)$, local haematoma $(n=9 ; 0.83 \%$ versus $n=13 ; 1.4 \% ; p=0.001)$, and local site paraesthesia $(n=13 ; 1.2 \%$ versus $n=19 ; 2.1 \% ; p=0.03$ ) were significantly higher in transfemoral than transradial group.

\section{Discussion}

Transradial approach for cardiac catheterization (TRC) is an appealing alternative to transfemoral access for both diagnostic and therapeutic purposes though it requires a steep learning curve initially. Because of its anatomy and inherent nature, technical challenges will always be there. Transradial access has been associated with a greater access crossover rate, which was reported to be $4 \%-7 \%$ in various studies [7-9]. Louvard et al. [10] reported the crossover from transradial to transfemoral approach in $8.9 \%$ and $8.1 \%$ vise versa in their patient's study. That might be because of octogenarian population, lesser number of patients enrolled, and mixed population of both angiography and percutaneous interventions. Kim and Yoon [11] in their study had crossover rate of $3.5 \%$ for TRC. In our study, however the crossover rate in TRC group was $2.8 \%$, while there was $0.3 \%$ crossover in transfemoral group. This was because of proper selection of suitable radial cases, accurate puncture technique, gentle and delicate maneuver of catheter, and methods for dealing with tortuous epiaortic anatomy. Puncture failure is the first obstacle during the early learning period of transradial catheterization because radial artery, being small, is prone to spasm. Wrist pain at puncture site is an important factor leading to radial spasm and puncture failure. As puncture is the gateway of radial access, it should be near perfect. Also, improvements in device technology and increase in expertise have narrowed the gap of access site crossover from the earlier period of transradial access to the modern era.

Louvard et al. [10] reported that fluoroscopy time was longer in transradial group than transfemoral group $(4.5 \pm$ 3.7 versus $6.0 \pm 4.4 \mathrm{~min} ; p<0.05$ ) for coronary angiography which sometimes becomes more demanding and longer in elderly patients because of the frequent presence of specific vascular abnormalities, calcification, or arterial loops. Plourde et al. [12] in their meta-analysis reported that transradial access was associated with a small but significant increase in fluoroscopy time for diagnostic coronary angiography which narrows down over time; the clinical significance of this small increase is uncertain and is unlikely to outweigh the clinical benefits of transradial access. Again, meta-regression analysis showed that overall difference in fluoroscopy time between the two procedures has decreased significantly by $75 \%$ over past two decades from 2 min to nearly $30 \mathrm{~s}$ ( $p<$ $0.0001)$ because of expertise and improved hardware, an observation similarly noted by Agostoni et al. [13] and Brasselet et al. [14]. Fluoroscopy time in our study too among both groups was not significantly different.

The procedural duration (from first puncture attempt to removal of last catheter) was 9.87 minutes as reported by Chag and Gupta [15]. Similar were the observations made by Brueck et al. [16]. All of them noted that left radial approach consumes lesser time than right radial approach though, in our study, the majority were done by right radial approach with procedural time of $9.33 \pm 2.82$, not significantly different from transfemoral group. In our study, most of them were single wall puncture which is considered to be ideal; some of them were done through puncture and retraction technique 
as well. Single successful puncture in first attempt thus cutting down the procedural time might have made a difference as well.

Contrast volume during the procedure was not significantly different among both groups though lesser in transradial group as noted by Rao et al. [17] and Kawashima et al. [18]. The higher percentage of post-CABG patients in the transfemoral in our study may partly account for the higher though not significant contrast dose in the femoral group and the subsequent significant higher utilization of radiation dose during procedure to visualize the graft bypass vessels in addition to native coronary arteries. Also this explanation can be applied to procedural times, which were longer in the femoral than the radial group; however, it did not reach a statistically significant difference. Postprocedural serum creatinine did not show any significant rise among both groups to show that risk of contrast induced nephropathy remains the same in both of the groups.

Radiations doses and the combination of DAP (dose area product) fluoroscopy and DAP fluorography were not different among both groups though Brueck et al. [16] had reported higher radiation exposure in transradial than transfemoral group. This was partly offset by larger number of post CABG cases in transfemoral group. We performed all transradial procedures with single preshaped catheter (Tiger catheter) and therefore we cannot exclude that the use of this one could contribute to a further reduction in radiation exposure thereby equating the two [19]. Also the operator's experience plays a major role in the success rate and procedure duration and therefore radiation exposure.

Incidence of RAO and vasospasm were similar as reported by Brueck et al. [16]. When patients with RAO were further examined, pulse was still palpable in $51 \%$ of patients. Local complications (local site pain, haematoma, and local site paraesthesia) were significantly higher in transfemoral group as reported by Jolly et al. [4].

Our results are from a high volume centre experienced in the transradial approach, and results might look different from laboratory with lower experience in this approach. As for the beginner in the transradial approach, it may consume extra time to access the radial artery compared with the experienced ones, and the fluoroscopy time may be longer but, as for the femoral approach, after adequate training, this gap narrows.

\section{Conclusion}

The transradial approach for coronary angiography is no longer merely an alternative strategy to transfemoral route but rather an excellent opportunity for operators to train for transradial coronary intervention.

\section{Competing Interests}

The authors declare that they have no competing interests.

\section{References}

[1] L. Campeau, "Percutaneous radial artery approach for coronary angiography," Catheterization and Cardiovascular Diagnosis, vol. 16, no. 1, pp. 3-7, 1989.
[2] F. Kiemeneij and G. J. Laarman, "Transradial artery PalmazSchatz coronary stent implantation: results of a single-center feasibility study," American Heart Journal, vol. 130, no. 1, pp. 1421, 1995.

[3] F. Kiemeneij, G. J. Laarman, and E. de Melker, "Transradial artery coronary angioplasty," American Heart Journal, vol. 129, no. 1, pp. 1-7, 1995.

[4] S. S. Jolly, S. Yusuf, J. Cairns et al., "Radial versus femoral access for coronary angiography and intervention in patients with acute coronary syndromes (RIVAL): a randomized, parallel group, multicentre trial," The Lancet, vol. 377, no. 9775, pp.14091420, 2011.

[5] International Commission on Radiological Protection, Conversion Coefficients for Use in Radiological Protection Against External Radiation, vol. 26, no. 3 of Annals of the ICRP, Publication 74, Elsevier, Oxford, UK, 1997.

[6] A. Sciahbasi, E. Romagnoli, F. Burzotta et al., "Transradial approach (left vs right) and procedural times during percutaneous coronary procedures: TALENT study," American Heart Journal, vol. 161, no. 1, pp. 172-179, 2011.

[7] F. Philippe, F. Larrazet, T. Meziane, and A. Dibie, "Comparison of transradial vs. transfemoral approach in the treatment of acute myocardial infarction with primary angioplasty and abciximab," Catheterization and Cardiovascular Interventions, vol. 61, no. 1, pp. 67-73, 2004.

[8] C. Pristipino, F. Pelliccia, A. Granatelli et al., "Comparison of access-related bleeding complications in women versus men undergoing percutaneous coronary catheterization using the radial versus femoral artery," The American Journal of Cardiology, vol. 99, no. 9, pp. 1216-1221, 2007.

[9] C. Pristipino, C. Trani, M. S. Nazzaro et al., "Major improvement of percutaneous cardiovascular procedure outcomes with radial artery catheterisation: results from the PREVAIL study," Heart, vol. 95, no. 6, pp. 476-482, 2009.

[10] Y. Louvard, H. Benamer, P. Garot et al., "Comparison of transradial and transfemoral approaches for coronary angiography and angioplasty in Octogenarians (the OCTOPLUS study)," The American Journal of Cardiology, vol. 94, no. 9, pp. 1177-1180, 2004.

[11] J.-Y. Kim and J. H. Yoon, "Transradial approach as a default route in coronary artery interventions," Korean Circulation Journal, vol. 41, no. 1, pp. 1-8, 2011.

[12] G. Plourde, S. B. Pancholy, J. Nolan et al., "Radiation exposure in relation to the arterial access site used for diagnostic coronary angiography and percutaneous coronary intervention: a systematic review and meta-analysis," The Lancet, vol. 386, no. 10009, pp. 2192-2203, 2015.

[13] P. Agostoni, G. G. L. Biondi-Zoccai, M. L. de Benedictis et al., "Radial versus femoral approach for percutaneous coronary diagnostic and interventional procedures: systematic overview and meta-analysis of randomized trials," Journal of the American College of Cardiology, vol. 44, no. 2, pp. 349-356, 2004.

[14] C. Brasselet, T. Blanpain, S. Tassan-Mangina et al., "Comparison of operator radiation exposure with optimized radiation protection devices during coronary angiograms and ad hoc percutaneous coronary interventions by radial and femoral routes," European Heart Journal, vol. 29, no. 1, pp. 63-70, 2008.

[15] M. Chag and S. Gupta, "Transradial interventions: our experience," Indian Heart Journal, vol. 62, no. 3, pp. 264-266, 2010.

[16] M. Brueck, D. Bandorski, W. Kramer, M. Wieczorek, R. Höltgen, and H. Tillmanns, "A randomized comparison of transradial versus transfemoral approach for coronary angiography 
and angioplasty," JACC: Cardiovascular Interventions, vol. 2, no. 11, pp. 1047-1054, 2009.

[17] S. V. Rao, F.-S. Ou, T. Y. Wang et al., "Trends in the prevalence and outcomes of radial and femoral approaches to percutaneous coronary intervention. A Report From the National Cardiovascular Data Registry," JACC: Cardiovascular Interventions, vol. 1, no. 4, pp. 379-386, 2008.

[18] O. Kawashima, N. Endoh, M. Terashima et al., "Effectiveness of right or left radial approach for coronary angiography," Catheterization and Cardiovascular Interventions, vol. 61, no. 3, pp. 333-337, 2004.

[19] S.-M. Kim, D.-K. Kim, D.-I. Kim, D.-S. Kim, S.-J. Joo, and J.-W. Lee, "Novel diagnostic catheter specifically designed for both coronary arteries via the right transradial approach. A prospective, randomized trial of Tiger II vs. Judkins catheters," International Journal of Cardiovascular Imaging, vol. 22, no. 3-4, pp. 295-303, 2006. 